\title{
Ecologo-toxicological aspects of irrigation of lands in conditions of technogenic load and provision on detoxication of «soil-plant» system
}

\author{
L. Vorotyntseva, \\ Candidate of Agricultural Sciences \\ National Scientific Center «Institute of Soil Science and Agrochemistry named after O.N. \\ Sokolovsky»
}

The purpose. Study of influence of technogenic load upon state of irrigating waters, soils and quality of agricultural products in conditions of sewaged agro-landscapes of Donetsk and Kherson oblasts (in particular Ingulets irrigation system), development of differentiated provisions on detoxication of «soil-plant» system. Methods. Field, analytical, statistical. Field researches spent in conditions of monitoring diagnostic studies and in microplot experiences. Results. By long researches it is fixed that in conditions of technogenic load aggravation of ecological state of irrigating waters, soils, contamination of agricultural products by heavy metals is registered. On the basis of assessment of state of agro-lanscapes they determine directions of their agricultural use or rust-preventive treatment of lands and provisions on detoxication of «soil-plant» system (physical, chemical, biological). Conclusions. With the purpose of minimization of risk of degradation of sewaged agro-landscapes and lowering reclamative load on soils the ecological setting of man impact, application of system of provisions on detoxication, reestablishment of fertility of low-purity soils and lowering translocation of metals in grown crops that is one of the important components of the strategy of balanced use of irrigated lands is necessary.

Key words: heavy metals, detoxication, irrigating, irrigating water, ecological setting, technogenic load, typical black earth, phytomelioration.

Formulation of the problem. Today, in the world, considerable attention is devoted to global climate change and the development of adaptation ways to ensure sustainable and balanced land use [1-3]. The Intergovernmental Panel of Experts of the United Nations was created to analyze the causes of this phenomenon and possible dangerous consequences, to develop concepts and options for adapting agricultural production to changes in natural conditions in different countries.

The arid climate causes a significant increase in the deficit of water supply and the expansion of the territory with a deficit of natural moisture content, the area of which has increased by 8 million hectares over the past 30-50 years [4]. Under such conditions, the role of irrigation as a stabilizing factor in agrarian production is greatly increased in order to obtain sustainable crops for the purpose of ensuring food security of the country. In this connection, a Coordinating Council on the Restoration and Development of Irrigation Systems has been established in Ukraine.

However, much attention should be paid to monitoring the state of water and soil resources, assessing their quality status, balanced land and water use, environmental security as a result of the growth of the rate, extent and extent of land degradation noted by FAO representatives $[5,6]$.

In regions with difficult environmental situation and high anthropogenic load on the environment the use of irrigated land is compounded by pollution of heavy metals (HM), which calls for monitoring studies to assess environmental and land improvement status agrolandscapes, organization of permanent control over the content of pollutants justification environmentally acceptable levels and modes of land use, environmental regulation stress and develop measures to reduce heavy metals in soils and intake into plants.

The purpose of the research is to study the impact of technogenic loading on the condition of irrigation water, soil and quality of agricultural products under irrigated agro-landscapes of the Donetsk and Kherson regions (in particular, Ingulets irrigation system, development of differentiated measures for detoxification of the soil-plant system). 
Research methodology. The objects of research are irrigated agrolandscapes of Donetsk and Kherson regions (Inguletska IS), which are subject to different intensity of anthropogenic influence. Their soil cover is represented by chernozems, usually light and medium-humus, mostly heavy-grained and light-grit granulometric composition, and dark chestnut, naturally salinized or secondary salted by soil irrigation.

At the core of research it is the implementation of multi-year integrated monitoring surveys of irrigated lands, the laying of stationary monitoring sites using the "key-analogues" method in accordance with existing methods [7]. Methods of detoxification (phytomelioration and selection of resistant cultures) were studied in micro-dipole experiments, laid on chernozem ordinary weakly alkaline in the conditions of the Northern Steppe, against the background of soil pollution with lead and cadmium.

The content of available forms of $\mathrm{HM}$ in soil was determined by atomic absorption method with extraction by acetate-ammonia buffer solution with pH-4,8 (DSTU 4770.1: 2007- 4770.9: 2007). The quality of irrigation water according to environmental criteria was assessed according to State Standard of Ukraine 7286-2012. Analysis of long-term data was carried out using statistical methods.

Research results. The quality of irrigation water in technogenic regions is formed mainly under the influence of anthropogenic factors (discharges of sewage from coal mines, industrial enterprises, atmospheric emissions), which are offset by natural factors. The investigated objects vary according to sources and quality of irrigation water. So, in the Donetsk region, irrigation is carried out from numerous small sources (rivers, ponds, reservoirs), which differ in their chemical composition and suitability for irrigation, compared with the Ingulets irrigation system.

Thus, our previous studies have established [8] that with waters of 1class by the HM content was watered only $10 \%$ of the territory, 2 nd class $-65 \%$ and $3 r d-25 \%$. Priority pollutants limiting the quality of irrigation water are lead, cadmium and cobalt. According to the level of soil contamination (layer 0-100 cm), the areas with an acceptable category $(\mathrm{Zc}<16,0)$ are $5 \%$ of the irrigation area, with moderately dangerous $(\mathrm{Zc}=16,1$ $32,0)-50 \%$ and dangerous $(\mathrm{Zc}=32,1-128,0)-45 \%$, which is associated mainly with the quality of irrigation water, but may be affected by the local influence of atmospheric pollution.

Subsequent long-term studies on stationary objects in this region have established that with increasing irrigation time of limited conventional and unusable waters load on chernozem ordinary increases and it is the negative impact of $\mathrm{HM}$ on the ecological state of soils increases, which requires ecological standardization, differentiated use of land and control over the quality of agricultural products.

The assessment of the quality of irrigation water in natural sources showed a slight variation in the content of the HM during the research period (Table 1), mainly within the gradation of one class, indicating a constant anthropogenic load, which is offset by natural factors.

1. The content of HM in irrigation water during the research period

\begin{tabular}{|c|c|c|c|c|c|c|c|c|c|c|}
\hline \multicolumn{9}{|c|}{ The content of heavy metals, $\mathrm{mg} / \mathrm{dm} 3$} & \multirow{2}{*}{\multicolumn{2}{|c|}{$\begin{array}{l}\text { Irrigation assessment } \\
\text { according to } \\
\text { environmental criteria }\end{array}$}} \\
\hline Zn & Mn & $\mathbf{F e}$ & $\mathrm{Cu}$ & $\mathbf{N i}$ & Co & $\mathbf{P b}$ & Cd & $\mathrm{Cr}$ & & \\
\hline \multicolumn{11}{|c|}{ Siversky Donets Donbass Channel (Slavonic district of Donetsk region) } \\
\hline 0,018 & 0,007 & 0,015 & 0,005 & 0,006 & 0,004 & 0,018 & 0 & 0,003 & \multicolumn{2}{|l|}{ I cl. } \\
\hline \multicolumn{11}{|c|}{ Kalmius River (City district of Donetsk) } \\
\hline 0,006 & 0,038 & 0,048 & 0,005 & 0,039 & 0,034 & 0,048 & 0,006 & 0,004 & \multicolumn{2}{|c|}{ II кл. за $\mathrm{Pb}, \mathrm{Cd}, \mathrm{Co}$} \\
\hline \multicolumn{11}{|c|}{$\frac{1}{\text { Kurakhove Reservoir (Mariinsky district Donetsk region.) }}$} \\
\hline 0,007 & 0,059 & 0,123 & 0,004 & 0,058 & 0,055 & 0,065 & 0,009 & 0,009 & \multicolumn{2}{|c|}{$\begin{array}{l}\text { III cl. за Pb, Co, } \\
\text { II cl. by Cd }\end{array}$} \\
\hline \multicolumn{11}{|c|}{ Ingulets IS (Kherson region) } \\
\hline 0,003 & 0,002 & 0,005 & 0,001 & 0,001 & 0,001 & 0,001 & 0,001 & 0,001 & $\min$ & $\mathrm{I} \mathrm{cl.}$ \\
\hline 0,075 & 0,091 & 0,404 & 0,006 & 0,019 & 0,069 & 0,032 & 0,001 & 0,022 & $\max$ & $\begin{array}{l}\text { III cl. by Co, I } \\
\text { cl. by } \mathrm{Pb}\end{array}$ \\
\hline 0,027 & 0,037 & 0,111 & 0,003 & 0,011 & 0,013 & 0,016 & 0,001 & 0,008 & average & I cl. \\
\hline
\end{tabular}


The quality of water in the Ingulets main channel is mainly formed depending on the ratio at the main water intake of the mineralized waters of Ingulets River, which contains the mine depletion waters of Kryvyi Rih, and fresh water of the Dnieper, which is associated with fluctuations in the qualitative composition of irrigation water during the period Studies (Table 1).

The mineralization of water in the main and distribution channels varied from 0,5 to $1,9 \mathrm{mg} / \mathrm{dm}^{3}$, the type of salts is mainly sulfate-chloride magnesium-sodium, $\mathrm{pH}$ - within the neutral $(7,0-7,5)$. But in some years mineralization of water could reach $3.5-5.7 \mathrm{mg} / \mathrm{dm}^{3}$, which creates a certain ecological danger for using it for irrigation [9].

According to environmental criteria, water was evaluated mainly as suitable for irrigation, but in separate monitoring periods, its quality varied to a limitable suitable and unusable for irrigation. Elements that most often limit the suitability of water are lead and cobalt. Significant amplitude of fluctuations in the values of the contents of the HM is noted, which testifies to the influence of anthropogenic factor on the formation of water quality and requires constant monitoring to prevent soil contamination and crop production.

By irrigation in the upper layers of chernozem ordinary, a tendency has been observed regarding the increase in the concentration of available forms of $\mathrm{HM}$, the excess content of which leads to deterioration of soil quality (Table 2). In chernozems common in irrigated water of poor quality (II, III class), their content increased by an average of 2-10 times compared with soils irrigated with water of the I class and their irreducible analogues, and the category of pollution increased to moderately dangerous and dangerous, with the arrival of HM with irrigation water, as well as through the transition of their compounds into a more soluble form for improving the water regime.

Priority pollutants of soil are lead, cadmium, cobalt, nickel, whose concentration exceeded the background content in 1,3-10,0 times. Irrigation enhances the migratory ability of the HM, which results in the formation of a recovered and accumulative horizons (at a depth of 50-100 cm).

In the dark chestnut soils of the Ingulets IS there was a significant amplitude of the fluctuations of the content of available metal forms and the increase of nickel concentration, cobalt, lead, copper for irrigation (Table 3). However, it should be noted that in the arable layer of investigated soils only the average content of nickel and lead exceeded the background values in 1.6-2.2 times, and the category of contamination was within the permissible one (Zc <16). In a layer of $50-100 \mathrm{~cm}$, accumulation of cadmium, nickel, cobalt, chromium and raising the level of pollution to a moderately hazardous category $(\mathrm{Zc}=16-32)$ is noted, which poses a threat due to the possible translocation of toxicants into agricultural crops.

2. Influence of irrigation by waters of different quality on the content of available HM forms in chernozems ordinary, $\mathrm{mg} / \mathrm{kg}$

\begin{tabular}{|c|c|c|c|c|c|c|c|c|c|}
\hline Depth, cm & $\mathrm{Zn}$ & Cd & $\mathbf{N i}$ & Co & $\mathrm{Fe}$ & Mn & $\mathbf{P b}$ & $\mathrm{Cu}$ & $\mathrm{Cr}$ \\
\hline \multicolumn{10}{|c|}{ LLC "Technotreyd" (Slavic district) } \\
\hline $0-25$ & 0,20 & 0,21 & 0,46 & 0,50 & 5,00 & 5,20 & 0,55 & 0,20 & 0,18 \\
\hline $25-50$ & 0,50 & 0,35 & 0,60 & 0,60 & 4,00 & 2,53 & 0,48 & 0,50 & 0,43 \\
\hline \multicolumn{10}{|c|}{ LLC «Teplychnyi» (City district of Donetsk) } \\
\hline $0-25$ & 0,56 & 0,40 & 0,95 & 0,8 & 4,90 & 4,44 & 2,51 & 0,59 & 0,45 \\
\hline $25-50$ & 0,50 & 0,60 & 1,05 & 1,50 & 9,90 & 3,97 & 1,80 & 0,55 & 0,63 \\
\hline \multicolumn{10}{|c|}{ AF named dfter Gorky (Marinka district) } \\
\hline $0-25$ & 0,71 & 0,65 & 1,35 & 1,70 & 6,35 & 9,30 & 5,40 & 0,95 & 0,75 \\
\hline $25-50$ & 0,66 & 0,8 & 1,10 & 1,40 & 4,35 & 7,49 & 2,94 & 0,69 & 0,54 \\
\hline \multicolumn{10}{|l|}{ Without irrigation } \\
\hline $0-25$ & 0,35 & 0,10 & 0,40 & 0,30 & 2,7 & 5,98 & 0,44 & 0,15 & 0,21 \\
\hline $25-50$ & 0,50 & 0,20 & 0,50 & 0,18 & 5,1 & 5,14 & 0,48 & 0,40 & 0,11 \\
\hline Background [8] & 1,0 & 0,1 & 1,0 & 0,5 & 2,0 & 43,0 & 0,5 & 0,5 & 0,1 \\
\hline
\end{tabular}


3. The content of available forms of HM in dark chestnut soils, $\mathrm{mg} / \mathrm{kg}$

\begin{tabular}{|c|c|c|c|c|c|c|c|c|c|}
\hline Content of HM & $Z \mathbf{n}$ & Cd & $\mathrm{Ni}$ & Co & $\mathrm{Fe}$ & $\mathbf{M n}$ & $\mathbf{P b}$ & $\mathrm{Cu}$ & $\mathrm{Cr}$ \\
\hline \multicolumn{10}{|c|}{ Irrigation, $0-25 \mathrm{~cm}$} \\
\hline Minimum & 0,04 & 0,01 & 0,38 & 0,07 & 0,06 & 3,27 & 0,01 & 0,05 & 0,06 \\
\hline Maximum & 0,69 & 0,35 & 3,08 & 1,22 & 4,03 & 51,19 & 3,67 & 0,70 & 3,21 \\
\hline Average & 0,28 & 0,14 & 1,65 & 0,40 & 1,27 & 20,97 & 1,12 & 0,27 & 0,89 \\
\hline \multicolumn{10}{|c|}{ Irrigation, $25-50 \mathrm{~cm}$} \\
\hline Minimum & 0,01 & 0,05 & 0,16 & 0,01 & 0,21 & 5,30 & 0,06 & 0,07 & 0,05 \\
\hline Maimum & 1,42 & 0,52 & 2,45 & 1,41 & 2,72 & 34,54 & 5,94 & 0,77 & 2,10 \\
\hline Average & 0,38 & 0,18 & 1,50 & 0,31 & 1,54 & 15,01 & 2,03 & 0,30 & 0,66 \\
\hline \multicolumn{10}{|c|}{ Without irrigation, $0-25 \mathrm{~cm}$} \\
\hline Average & 0,49 & 0,13 & 0,88 & 0,31 & 1,32 & 19,19 & 0,53 & 0,69 & 1,05 \\
\hline \multicolumn{10}{|c|}{ Without irrigation, $25-50 \mathrm{~cm}$} \\
\hline Average & 0,42 & 0,13 & 0,67 & 0,33 & 0,92 & 14,76 & 0,80 & 0,32 & 0,94 \\
\hline Background [8] & 1,0 & 0,1 & 1,0 & 0,5 & 2,0 & 43,0 & 0,5 & 0,5 & 0,1 \\
\hline
\end{tabular}

Under a tense ecological situation, an important aspect is the quality control of products, since excessive amounts of HMs in the soil can lead to increased translocation and accumulation of toxic substances in plants, posing a threat to human health.

The evaluation of cereals, fodder and vegetable crops grown under the conditions of the Ingulets Irrigation System showed that it was pure in relation to HM, but in certain irrigated soils in wheat and sunflower seeds the lead, cadmium, chromium content exceeded the maximum allowable concentrations (MAC) and the maximum allowable Levels (MAL).

For the conditions of the Donetsk region with irrigation by contaminated waters, as well as the aerial flow of metals, there is an increase in their translocation in plants and pollution of products. Thus, in vegetable products for irrigation by inappropriate waters (Gorky, Marinsky district), the content of the most common pollutants - lead and cadmium exceeded the MPC by 1.2-2.5 times.

It should be noted that the development of degradation processes in soils leads to economic losses, which are due to the loss of income and profit of agrarian enterprises due to reduced yields of cultivated crops and reduction of gross tax. Thus, for a weak degree of degradation as a result of pollution of the HM, the reduction of crop yields to $10 \%$, the average - $10-20 \%$, and the strong - more than $20 \%$.

Thus, the obtained results of researches show that in regions with high technogenic loading the development of methodological bases of ecological standardization is urgent, the purpose of which is the establishment of obligatory norms, rules, regulations on land use, compliance with ecological and sanitary and hygienic safety requirements with the aim of minimization of the degradation risk of irrigated agro-landscapes, as well as reducing the reclamation effect on soils [5].

Environmental regulation aims at preventing the negative effects of anthropogenic impacts on ecosystems, including on soils, to ensure sustainable functioning and to achieve a balance between negative anthropogenic impact and the ability of the soil to recover. The result of ecological standardization is the definition of the maximum allowable load on the soil system - the maximum load, which does not cause undesirable changes in the ecosystem, which maintains the biotic and energy balance, the stability of the soil system and the maintenance of productive and ecological functions within optimal limits.

The question of the regulation of the content of metals in soils and plants is extremely difficult due to the impossibility of fully taking into account the influence of all factors of the natural environment. It can be based, for example, on agronomic and sanitary-hygienic approaches [1], based on the size of the crop, the quality of products, the content of metals in the soil.

To regulate the content of toxic substances, the maximum allowable and approximate tolerable concentrations of $\mathrm{HM}$ are used, but they do not always allow an objective assessment of the level of contamination of the components of agroforestry. Therefore, taking into account the variability of soil cover, as 
well as the different biological capacity of crops to limit the flow of metals into vegetative and generative organs, it is necessary to abandon single Maximum Allowable Concentration for all types of soils.

Depending on the ecological and agro-amelioration status of irrigated land, areas of further use of land in agricultural production are determined and measures are being developed to detoxify the soil-plant system. If the level of environmental degradation reached a high level, then the agricultural use of such land is inappropriate.

Nowadays, it is stated at the legislative level that degraded, technogenically polluted land whose use is environmentally hazardous, economically ineffective and does not allow ecologically pure products to be extracted from circulation and preservation (Articles 170, 172 of the Land Code of Ukraine, "Land Conservation Procedure ", Approved by the orders of the State Committee of Ukraine for Land Resources (No. 175 dd. 17.10.2002) and the Ministry of Agrarian Policy of Ukraine (No. 283 dated April 26, 2013).

On the land with weak and medium degradation, a measures system of detoxification, restoration of fertility of contaminated soil and reduction of translocation of HM in cultivated crops is used, which is one of the important components of the strategy of balanced use, reproduction and management of Ukrainian soil resources.

On the basis of analysis and generalization of the results of long-term studies, recommendations [11] were prepared, in which the main measures (physical, chemical, biological) for reducing the toxic effect of the HM in the "soil-plant system" are described, including the introduction of ameliorants and adsorbents of different nature into the soil; soil flushing using special substances that increase solubility of compounds of HM; phytomelioration; selection of crop resistant plants; bioremediation using microorganisms.

A common chemical method is the use of adsorbents, for example, iron-calcium, calcium ameliorants, the positive effect of which is due to the formation of complex compounds, as well as the saturation of the soil absorb complex with calcium, which improves the physical and chemical properties of the soil. In the micro units, the detoxification of contaminated chernozem with the use of iron-calcium sludge of steel-wire production had a positive effect, which was manifested in reducing the content of available forms of pollutants in the soil, reducing their translocation in plants and increasing the yield of crops by $10-59 \%$ : winter wheat - by $16-19 \%$, buckwheat - $33-59 \%$, corn $-17-21 \%$, fodder beet $-21 \%$, alfalfa - $10 \%$, potatoes $-24 \%$.

For soils with a low degree of contamination it is expedient to use ecologically safe methods of detoxification of contaminated soils - biological, which are based on the use of the metabolic potential of biological objects, such as plants, microorganisms.

Phytomelioration measures include growing on contaminated soils of plants that can accumulate and carry a large amount of toxic substances with biomass, due to the significant content of specific cells that can bind metals, weakening their toxic effects and retaining the ability to reproduce other plant cells.

The advantages of this method are ecological cleanliness, safety of use, minimal impact on soil properties, low cost of application [11], but it is a long-term one. For the phytoextraction of HM from the soil, it is possible to use both crops and wild plants (Sakhalin buckwheat, superfruit, garlic, Sareptic mustard).

In the micro-dipole experiment, phytomelioration of chernozem, contaminated with lead and cadmium (on 50 backgrounds of each element), perennial forage grasses, a stomach ulcerous, alfalfa blue, and esparsetium were studied. Among them, the highest yields were burkun, espartset and alfalfa.

For the quantitative estimation of the flow of HM from soil to plants, a coefficient of biological accumulation (CBA) was used which was calculated as the ratio of concentrations of pollutants in phytomass of plants and soils. The results showed (Fig. 1) that cadmium is an element of weak accumulation $(C B N<1)$ for all cultivated crops.

The highest values of this indicator are characteristic for alfalfa, esparzet (0.19-0.21). Lead was characterized as a heavy metal ( $\mathrm{CBN}>1)$, but with a higher translocation there was a green mass of alfalfa (CBN-2,16). Calculation of HM removal also confirms that the highest ability of alfalfa and esparset was different - 3.8-4.2 kg/ha, that is to clean the soil to the background level it is necessary to $55-60$ years, which confirms the necessity of combining chemical and biological methods of detoxification at high levels of soil pollution. 


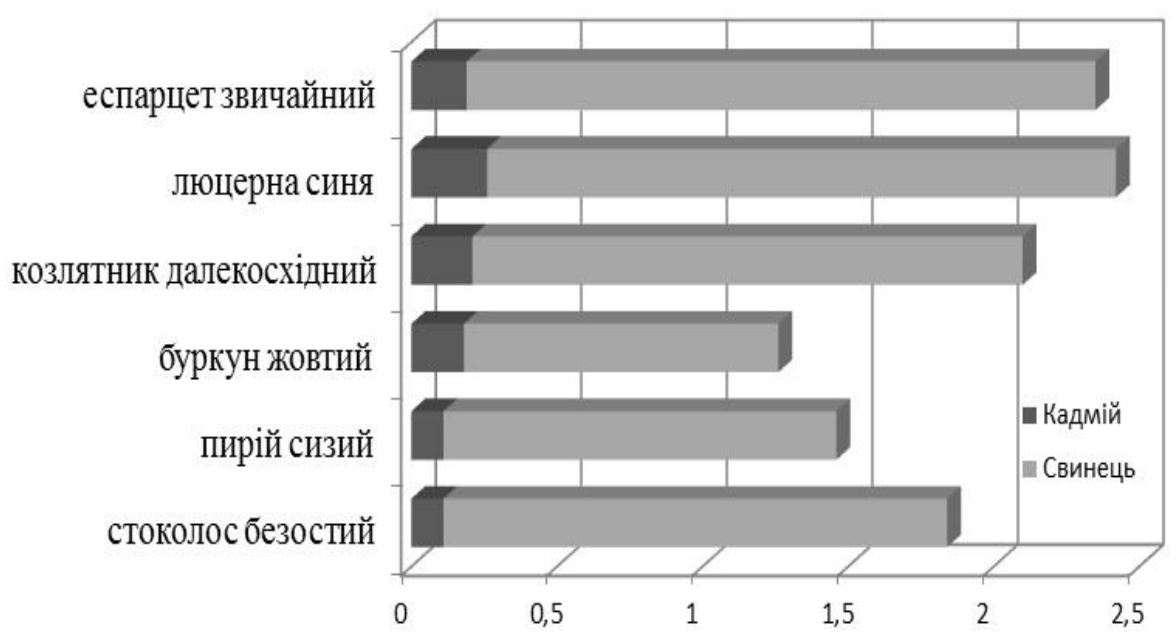

Fig. 1 - Coefficients of biological absorption of lead and cadmium by fodder crops

Our studies on the resistance to the action of $\mathrm{HM}$ and the phytoextraction of pollutants with annual cultures (Sudan grass, sorghum-sodic hybrid, radish oilseed, sorghum silage, sunflower, corn, mustard on green fodder, peas) on chernozem ordinary, contaminated with cadmium (at the level of 50 backgrounds ) found that the highest yield and resistance to the toxic effects of cadmium were characterized by sunflower, corn, peas, sorghum, pike perch and radish oil, so the data of culture may be recommended for cultivation on contaminated given metal soils. The highest removal of the HM was characterized by radish oilseed and peas respectively 4.6 and $2.2 \mathrm{~kg} / \mathrm{ha}$.

\section{Conclusions}

With technogenic loading, the deterioration of the ecological condition of irrigated agro-landscapes is observed, which is to increase the concentration of HM in irrigated water, soils (chernozems ordinary and dark chestnut), increase their migration capacity and accumulation in agricultural products depending on the level of man-made and reclamation influence. In order to prevent the development of degradation processes and reduce the translocations of toxicants into agricultural products at different levels of contamination, a complex of measures for detoxification has been proposed.

\section{References}

1. Report of the second meeting of the plenary assembly of the Global Soil Partnership.- Rome, 22-24 July 2014. - $26 \mathrm{p}$.

2. Climate Change 2007: Synthesis Report. Contribution of Working Groups I, II and III to the Fourth Assessment Report of the Intergovernmental Panel on Climate Change. Core Writing Team, Pachauri, R.K. and Reisinger, A. (Eds.) - IPCC.- Geneva, Switzerland, 2007. - 104 p.

3. Liana Ricci Reinterpreting Sub-Saharan Cities through the Concept Of Adaptive Capacity. An Analysis of Autonomous Adaptation in Response to Environmental changes in Peri-Urban Areas. - Sapienza, 2016. - 211 p.

4. Concept of Irrigation Recovery and Development in the Southern Region of Ukraine; for ed. E. Romashchenko - K., 2014. - 27 p.

5. National Program of Soil Protection of Ukraine; for ed. S.A. Baliuk, V.V. Medvedev, M.M. Miroshnychenko - Kharkiv, 2015. - 59 p.

6. Claudia Ringler, Asit K. Biswas, Sarah A. Cline (Eds) Global Change: impacts on Water and Food Security. - Springer - Verlag Berlin Heidelberg, 2010. - 261 p.

7. Instruction on soil-salt survey on irrigated lands of Ukraine: GNI 33-5.5-11-02. - K .: State Committee for Water Management of Ukraine 2002. - 40 p. 
8. Protection of water, soil and vegetation resources of the Donetsk region from heavy metal contamination under irrigation conditions: Guide to the GNI 33-5.5-06-99 "Protection of water, soil and vegetation resources from contamination by heavy metals under irrigation conditions".- Kharkiv, 2002. - $49 \mathrm{p}$.

9. Baliuk S.A. The current state of irrigated lands in the Ingulets Irrigation System and ways to improve it/S.A. Baliuk, O.A. Nosonenko, L.I. Vorotyntseva [and others]// The guide of Ukrainian grain growers. - 20014. - № 3. - P. 52-54.

10. Concept of ecological standardization of permissible man-made loading on soil cover; for ed. S.A. Baliuk, M.I. Romashchenko - K.: Agrarian Science, 2004. - 34 p.

11. Measures to detoxify contaminated soils and reduce the translocation of heavy metals to crops//Recommendations/ S.A. Baliuk, L.I. Vorotyntseva, V.Ya.Ladnykh. - Kharkiv: Smuzhasta Typography Ltd., 2014. -56 p. 